\title{
POEMS Syndrome
}

National Cancer Institute

\section{Source}

National Cancer Institute. POEMS Syndrome. NCI Thesaurus. Code C80303.

A syndrome characterized by polyneuropathy, organomegaly, endocrinopathy, monoclonal gammopathy, and skin changes. It is often associated with osteosclerotic myeloma. 